\title{
Effect of Process Factors on Viscosity of In-situ Particulate Reinforced Aluminum Matrix Composites
}

Zhi-Hong JIA ${ }^{1, a,{ }^{*}, \text { Dao-Cun XIE }}{ }^{2, b}$, Lan-Lan XIONG ${ }^{3, c}$, Chi ZHANG ${ }^{3, c}$, Yu-Tao ZHAO ${ }^{3, c}$

1,2,3 School of Material Science \& Engineering, Jiangsu University, Zhenjiang 212013, China

ajia_zh@163.com, ${ }^{b} 1057426394 @ q q . c o m,{ }^{c} 1176583168 @ q q . c o m$

* Corresponding author

Keywords: Viscosity, Aluminum Matrix Composites, $\mathrm{TiB}_{2}$ Particulate, Content of $\mathrm{Si}$, Superheat.

\begin{abstract}
Viscosity of aluminum matrix composites reinforced by $\mathrm{TiB}_{2}$ particle has been studied systematically by using the rotating cylinder method. The results show that the viscosity of melt decreased with the increase of temperature, and the changes are abnormal when the temperature is between $710^{\circ} \mathrm{C}$ to $730^{\circ} \mathrm{C}$. In high superheat, the viscosity of melt decreased with the increase of $\mathrm{Si}$ content. It is more then $11 \% \mathrm{Si}$ content that the viscosity of the melt increased in low superheat.
\end{abstract}

\section{Introduction}

In-situ preparation of $\mathrm{TiB}_{2}$ particle reinforced aluminum composite was a new composite preparation technology which has been developed in recent decades[1]. Composite of stable performance can be obtained because of good interfacial compatibility between reinforced particle and substrate material[2-3]. $\mathrm{TiB}_{2}$ has the properties of high melting point, high hardness, high elasticity modulus, good corrosion resistance and abrasive resistance etc[4], that makes $\mathrm{TiB}_{2} / \mathrm{Al}$ composite become an excellent structural material[5].

Viscosity is a physical property of liquid metal which describe the melt structure change[6-8]. The information of distribution, aggregation, and sediment of melt particles can be obtained by studying the composite melt particles, thus improving the preparation process of particulates reinforced composites. It provides theoretical basis for making composites which have uniformly distributed and fine grained particulates[9-11]. Containing reinforcing particles makes the metal liquidity worse and influences the mold filling capacity of the melt. The impact of different factors on melt viscosity of TiB2 reinforced composites was studied in this paper.

\section{Experimental Procedures}

$\mathrm{Al}($ better than $99.9 \%$ ) and $\mathrm{Al}-20 \% \mathrm{Si}$ alloy were used to produce $\mathrm{Al}, \mathrm{Al}-1 \% \mathrm{Si}, \mathrm{Al}-3 \% \mathrm{Si}, \mathrm{Al}-5 \% \mathrm{Si}$, Al-11\% Si alloy by the mass fraction. According to precious study [12-14], K2TiF6、 KBF4 and Ti were used as reactant to prepare 3\% TiB2 aluminum matrix composites by resistance furnace.

The prepared Al, Al-1\%Si, Al-3\%Si, Al-5\%Si, Al-11\%Si samples were taken into clay crucible. The samples were smelted in 30kw well resistance furnace(SG2-5-10 model Well type); the liquid metal was refined with slag removal in $850^{\circ} \mathrm{C}$, and let stand for 10 minutes. $\mathrm{K}_{2} \mathrm{TiF}_{6}$ and $\mathrm{KBF}_{4}$ were added to the melt in a certain proportion, and the melt was stirred well by carbon rod. After 30 minutes, the liquid metal with degassing and slag removal was poured in copper mold in $750^{\circ} \mathrm{C}$. Then as-cast composite can be obtained.

The reaction of producing in-situ $\mathrm{TiB}_{2}$ particulate reinforced aluminum matrix composites is:

$$
3 \mathrm{~K}_{2} \mathrm{TiF}_{6}+6 \mathrm{KBF}_{4}+10 \mathrm{~A} 1 \rightarrow 2 \mathrm{TiB}_{2}+6 \mathrm{AlF}_{3}+12 \mathrm{KF}+\mathrm{TiAl}_{3}+\mathrm{A}_{1 \mathrm{~B}_{2}}+6 \mathrm{~F}_{2}
$$

$\mathrm{TiA} 13+\mathrm{AlB} 2 \rightarrow \mathrm{TiB} 2+4 \mathrm{Al}$ 
Viscosity measuring instrument: GNDJ high temperature melt viscosity instrument, NDJ-5S digital Viscometer, the structure is shown in Ref.15.

\section{Results and Analysis}

\section{Relationship between Temperature and Viscosity}

Metal melt viscosity usually keep declining with the increase of temperature[11]. Figure 1 shows the relationship between temperature and melt viscosity of $3 \%$ (mass fraction) $\mathrm{TiB}_{2}$ composites.

Adding $3 \% \mathrm{TiB}_{2}$ particles, apparent viscosity of the four different constituents composites has the same change trend in $620^{\circ} \mathrm{C} \sim 800^{\circ} \mathrm{C}$. Viscosity-temperature curve shows that, with the increase of temperature, viscosity decreased firstly then increased rapidly, afterwards decreased slowly. In $775^{\circ} \mathrm{C} \sim 800^{\circ} \mathrm{C}$ temperature interval viscosity continue to increase.

For pure aluminum and $1 \% \mathrm{Si}$ sample, the melt temperature interval $\left(630^{\circ} \mathrm{C} \sim 800^{\circ} \mathrm{C}\right)$ can be divided into three section, they are: $660{ }^{\circ} \mathrm{C} \sim 730^{\circ} \mathrm{C}$ low temperature area; $730{ }^{\circ} \mathrm{C} \sim 750^{\circ} \mathrm{Cmedium}$ temperature area; $775{ }^{\circ} \mathrm{C}$ above high temperature area. For $5 \% \mathrm{Si}$ and $11 \% \mathrm{Si}$ sample, the same interval $\left(630^{\circ} \mathrm{C} \sim 800^{\circ} \mathrm{C}\right)$ can also be divided into three section: $660{ }^{\circ} \mathrm{C} \sim 715^{\circ} \mathrm{C}$ low temperature area; $715{ }^{\circ} \mathrm{C} \sim 775^{\circ} \mathrm{C}$ medium temperature area; $775{ }^{\circ} \mathrm{C}$ above high temperature area.
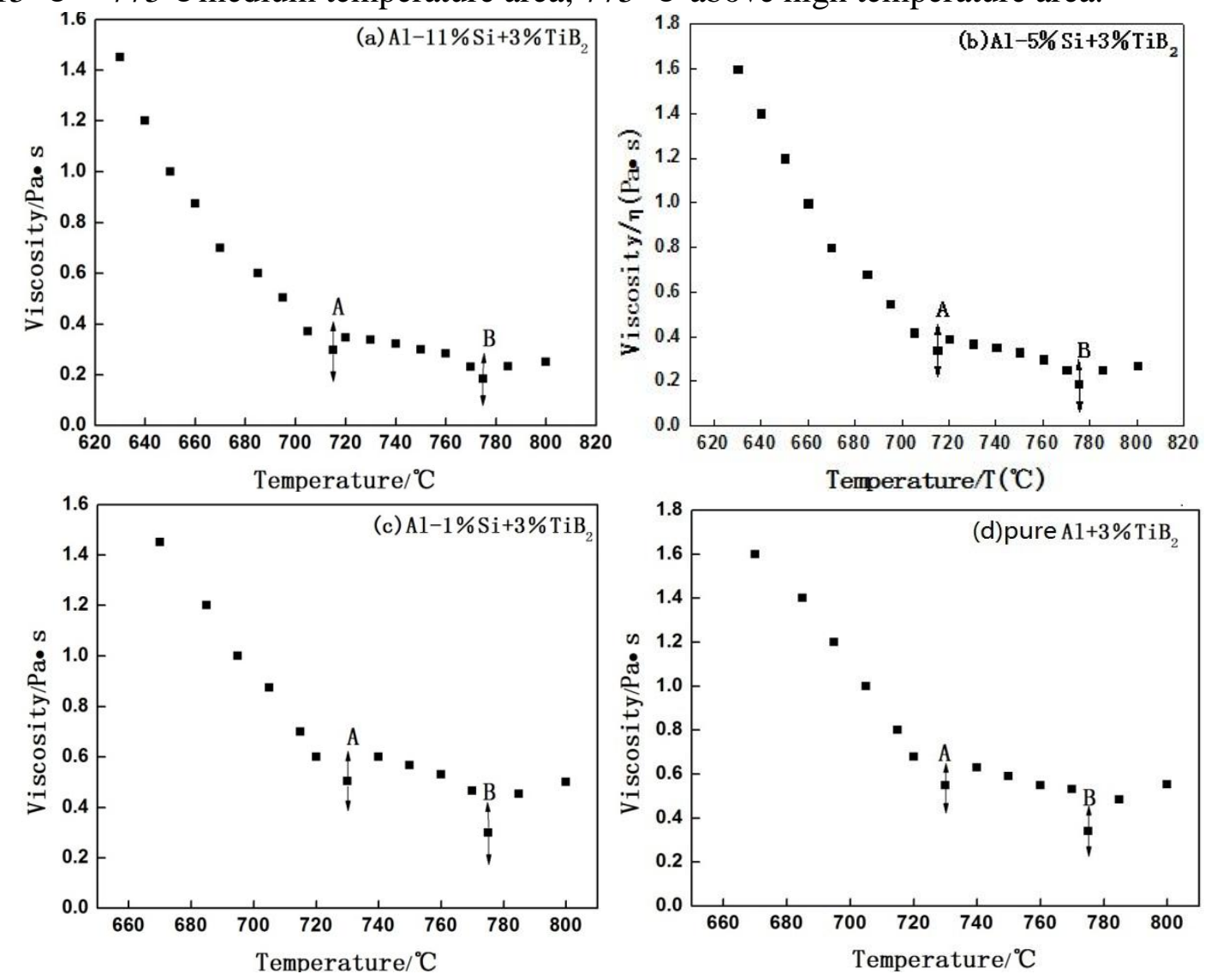

Fig.1 Relationship between viscosity of composite melts and temperature

In low temperature area, microscopic particles activity was more vigorous with increasing temperature. The force of substrate atoms and $\mathrm{TiB}_{2}$ particles gradually weakened, so viscosity decreased. $\mathrm{TiB}_{2}$ particles can be seen as "atomic cluster". With the increasing temperature and the continually stirring rotor, the distribution of melt atoms and $\mathrm{TiB}_{2}$ ceramic particles is more uniform, and the micro non-uniformity of melt is reduced. Therefore, average energy of viscosity flow interaction increases, it shows up as less melt stickiness on a macroscopic scale[16], that is, the viscosity presents an ascending trend in medium temperature area. This factor had more impact on viscosity than temperature, thus the first discontinuous change of viscosity happened. Literature[17] 
find that, melt viscosity increased with the increasing temperature by adding $3 \% \mathrm{TiB}_{2}$ into $\mathrm{Al}$ and rising temperature to $780^{\circ} \mathrm{C}$. It is considered that $\mathrm{Al}$ atoms reacted with oxygen in the air to form $\mathrm{Al}_{2} \mathrm{O}_{3}$ particles due to thermal motion of $\mathrm{Al}$ is fierce.

\section{Effect of Si Content on Melt Viscosity}

As seen in Fig.2, with the increase of Si content, four different kinds of melt viscosity decreased in the same temperature. According to Doolittle's formula about viscosity and free volume:

$$
\eta=A e^{B /\left(v_{f} / v_{0}\right)}
$$

In the formula, $\eta$ is viscosity coefficient; $v_{f} / v_{0}$ represents relative free volume ratio; $A$ and $B$ are constant for simple melt.

Cohen inheritance and development the theory about free volume in the liquid which has been presented by Eyring and Doolittle. According to Cohen's theory, it's 50 degrees lower of superheat in melt of pure $\mathrm{Al}$ and $3 \% \mathrm{Si}$ sample than in $11 \% \mathrm{Si}$ and $5 \% \mathrm{Si}$ sample under the same temperature. So hole concentration of atomic cluster increased in higher superheat melt, and size of atomic contraction increased. Combining formula (3), viscosity of $5 \% \mathrm{Si}$ and $11 \% \mathrm{Si}$ sample is lower.

Fig. 2 shows that, in pure $\mathrm{Al}$ and $3 \% \mathrm{Si}$ sample with $3 \% \mathrm{TiB}_{2}$, there is the first discontinuity in $730^{\circ} \mathrm{C}$ which is higher point than in $5 \% \mathrm{Si}$ and $11 \% \mathrm{Si}$ sample. One possible reason is that melt superheat degree reached $70{ }^{\circ} \mathrm{C}$ at this point, the size of many $\mathrm{Al}-\mathrm{Al}$ atom cluster decreased, and the number of free atom increased. Thus melt viscosity came down. For $5 \% \mathrm{Si}$ and $11 \% \mathrm{Si}$ sample, Superheat degree of melt has reached above $95{ }^{\circ} \mathrm{C}$ in $715^{\circ} \mathrm{C}$, meanwhile, Si-Si atomic clusters in $11 \% \mathrm{Si}$ sample melt and a small amount of $\mathrm{Si}-\mathrm{Si}$ atomic clusters in $5 \% \mathrm{Si}$ melt became small, so it made the viscosity decreased.

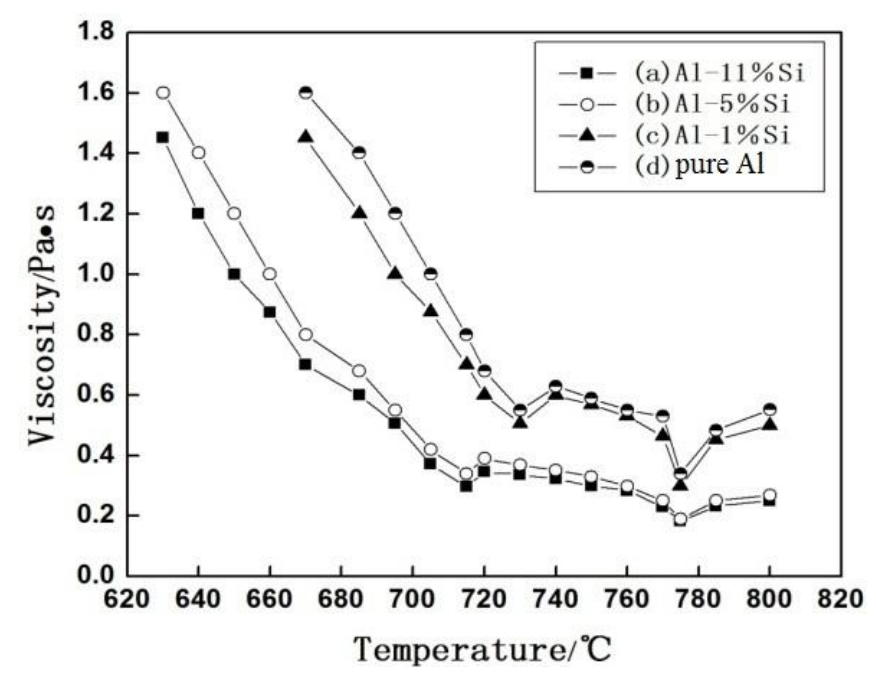

Fig.2 Relationship between viscosity of composites melt and temperature

The viscosity of the four kinds of melt changed suddenly in $775{ }^{\circ} \mathrm{C}$. One possible reason was that free atoms began to increase when temperature reached $775^{\circ} \mathrm{C}$, and they reacted with oxygen to form $\mathrm{Al}_{2} \mathrm{O}_{3}$ particles which made viscosity increase.

\section{Effects of Superheat on Viscosity}

According to Fig.3, when superheat degree was $\Delta \mathrm{T}=50^{\circ} \mathrm{C}$ and the Si content was below 5\%, with the increase content of $\mathrm{Si}$, viscosity decreased. One possible reason is that relatively few $\mathrm{Si}$ atoms led to less amount of $\mathrm{Si}-\mathrm{Si}$ atomic group. In contrast, viscosity increased when the content of $\mathrm{Si}$ was $11 \%$, because more $\mathrm{Si}-\mathrm{Si}$ atomic group formed in the melt and microscopic non-uniformity 
of melt was higher under low superheat. When the superheat degree reached $100^{\circ} \mathrm{C}$ or $150^{\circ} \mathrm{C}$, atomic motion became more violent, so the interaction between ceramic particle and matrix decreased and homogenized. In this conditions, microscopic distribution was more uniform, it showed that Si content have a smaller impact on melt viscosity in the macroscopic.

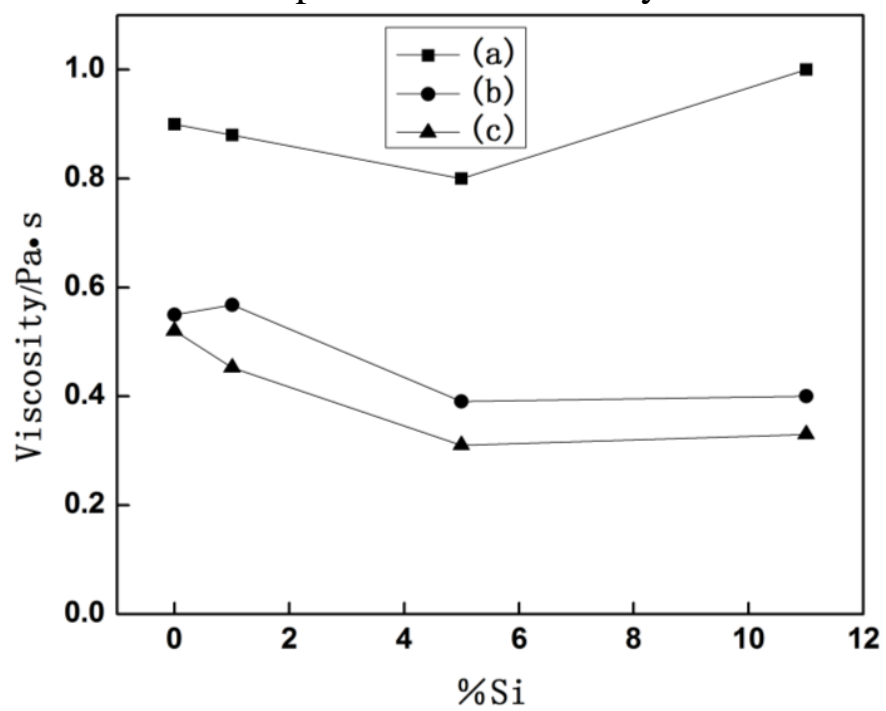

(a) $\Delta \mathrm{T}=50^{\circ} \mathrm{C} \quad$ (b) $\Delta \mathrm{T}=100^{\circ} \mathrm{C} \quad$ (c) $\Delta \mathrm{T}=135^{\circ} \mathrm{C}$

Fig.3 Comparison of the viscosities of $\mathrm{TiB}_{2}$ composite melts at the same superheat temperature

\section{Conclusion}

There are two points of discontinuity in TiB2 particle reinforced aluminum matrix composites with the increasing temperature: for pure aluminum or $1 \% \mathrm{Si}$ composite sample, one discontinuity point existed in $730^{\circ} \mathrm{C}$, another existed in $775^{\circ} \mathrm{C}$; for $5 \% \mathrm{Si}$ or $11 \% \mathrm{Si}$ composite sample, one discontinuity point existed in $715^{\circ} \mathrm{C}$ and another existed in $775^{\circ} \mathrm{C}$.

For $\mathrm{TiB}_{2}$ particle reinforced composites, viscosity decreased with the increasing content of $\mathrm{Si}$ in the same temperature.

When superheat degree reached $50^{\circ} \mathrm{C}$, the viscosity of $\mathrm{TiB}_{2}$ particle added composites decreased if $\mathrm{Si}$ content was below 5\%, while it increased if $\mathrm{Si}$ content was $11 \%$; when superheat degree was above $100^{\circ} \mathrm{C}$, because of more intense atomic motion, viscosity decreased with the increasing $\mathrm{Si}$ content.

\section{Acknowledgment}

The research was supported by National Natural Science Foundation of China (No.51174098), Zhenjiang science research project(GY2013032, GY2013052).

\section{Reference}

[1]Tjong S C, Ma Z Y, Microstructures and mechanical characteristics of in situ metal matrix composites, J. Mater Sci Eng A, 2000, A29: 49-113.

[2]Fan T, Zhang D, Yang G, Fabrication of in situ Al2O3/Al composite via remelting, J. Journal of Materials Processing Technology, 2003, 142: 556-561.

[3]Tjong C, Wang G S, Mai Y W, Low-cycle fatigue behavior of Al-based composites containing in situ TiB2, Al2O3and Al3Ti reinforcements, J. Mater Science Engineering, 2003, A358: 99-106.

[4]Wang Bao-long, Zhao Jun-guo, Wang Wen-wu, Properties of TiB2 material and its application in the aluminum industry, J.Light Metals, 2004,5:23-26. 
[5]Zhao Min, Wu Gao-hui, Dou Zuo-yong, $\mathrm{TiB}_{2}$ p/Al Composite Fabricated by Squeeze Casting Technology, J. Materials Science and Engineering, A374( 2004) : 303- 306.

[6]IIDA.T , GUTHRIE R.I.L, The physical properties of liquid metals, MD thesis, Oxford: Clarendon Press, 1993.

[7]Seetharaman S, Sichen.D, Estimation of the viscosities of binary metallic melts using gibbs energies of mixing, J.Metall. Mater. Trans, 1994, 25: 589 - 591.

[8]Andrade D , Bygden J, Seetharaman S, A model for estimation of viscosities of complex metallic and lonic melts, J. Metall. Mater. Trans, 1994, 25: 519 - 522.

[9]WANG Peng, MA Nai-heng, The Deposition of Particulate in the In Situ TiB2 Reinforced Aluminum Matrix Composites, J. Special Casting \& Nonferrous Alloys, 2004,2:30 32 .

[10]J.D.Tice,Adam.D.Lyon, Effects of viscosity on droplet formation and mixing in microfluidic channels, J.Analytica Chimica Acta, 2004,50 (7):73 77 .

[11]G.C.Kalur,B.D.Frounfelker, Viscosity Increase with Temperature in Cationic Surfactant Solutions Due to the Growth of Wormlike Micelles, J.Langmuir, 2005,21:10998 11004.

[12]Jing Hua, Microstructure and properties of ( $\mathrm{TiB} 2+\mathrm{Al} 3 \mathrm{Ti}) / \mathrm{Al}$ composite synthesized by direct melt reaction under ultrasonic fields, MD, Jiangsu University, Zhen Jiang,2012.

[13]Xu Meng, CHEN Gang, ZHAO Yu-tao, Investigation of In-Situ Prepared TiB2/7055 Aluminium Matrix Composite Under Electromagnetic Stirring, J. Foundry Technology, 2009, 58(12): $1233 \sim 1237$.

[14]WU Zhi-feng, CHEN Gang, ZHAO Yu-tao, Effect of fabrication process on the microstructure of in-suit $\mathrm{Al}_{3} \mathrm{Ti} / \mathrm{Al}$ composites, J. Journal of Functional Materials ,2011,42:457 459 .

[15]JIA Zhi-hong, XIONG Lan-lan,ZHU Xiang, Effect of Process Parameters on Viscosity of AlSi Alloy Melt', J. Journal of Materials Science and Engineering, 2013,31(3):414-417.

[16]TENG Xin ying, WANG Bin, WANG Zhi ming, GENG Hao ran, Fluidity of Molten Binary Fe-xC Alloy', J. Foundry Technology,2007,28(5):628-630.

[17]WANG Wen-ming, PAN Fu-sheng, LU Yun, Current status of development and application in SiCp/Al composites, J.Ordnance Material Science and Engineering, 2004, (3): 61 67. 